\title{
A normal calcium, low protein, low salt diet reduced recurrence of renal stones over 5 years
}

\author{
Borghi L, Schianchi T, Meschi T, et al. Comparison of two diets for the prevention of recurrent stones in idiopathic \\ hypercalciuria. N Engl J Med 2002 Jan 10;346:77-84. \\ QUESTION: In men with recurrent calcium oxalate stones and hypercalciuria, is a diet \\ containing a normal amount of calcium but reduced amounts of animal protein and salt \\ more effective than a traditional low calcium diet?
}

\section{Design}

Randomised (unclear allocation concealment*), blinded (outcome assessors),* controlled trial with 5 years of follow up.

\section{Setting}

An outpatient department in Parma, Italy.

\section{Patients}

120 men (mean age 45 y) who had idiopathic hypercalciuria (urinary calcium excretion $>300 \mathrm{mg} / \mathrm{d}$ ) on an unrestricted diet, recurrent formation of calcium oxalate stones ( $\geq 2$ colic episodes with expulsion of stones or radiographic evidence of retained stones), no known condition commonly associated with calcium nephrolithiasis, no previous visit to a stone disease centre, and no current treatment for prevention of recurrent stones. 103 men $(86 \%)$ completed the study (13 withdrew, 2 were lost to follow up, and 2 died).

\section{Intervention}

60 men were allocated to a normal calcium $(30 \mathrm{mmol} / \mathrm{d})$, low animal protein $(52 \mathrm{~g} / \mathrm{d})$, low salt $(50 \mathrm{mmol} / \mathrm{d})$ diet (intervention diet). They were given detailed written explanations to help them comply with the diet. 60 men were allocated to a low calcium diet and instructed to avoid milk, yoghurt, and cheese so that calcium intake would be reduced to $10 \mathrm{mmol} /$ day. Both groups were advised to avoid large quantities of oxalate rich foods (eg, walnuts, spinach, and chocolate) and to drink 2 to 3 litres of water/day.

\section{Main outcome measure}

First recurrence of a symptomatic renal stone or presence of a radiographically identified stone.

\section{Main results}

Analysis was by intention to treat. Kaplan-Meier analysis showed that over 5 years men who received the

Sources of funding: University of Parma; Italian Ministry for Universities and for Scientific and Technological Research.

For correspondence: Dr L Borghi, University of Parma, Parma, Italy. loris.borghi@unipr.it. intervention diet were less likely to have a recurrence of stones than were men who received the low calcium diet (table).

\section{Conclusion}

In men with recurrent calcium oxalate stones and hypercalciuria, a normal calcium, low animal protein, low salt diet reduced the risk for recurrent stones more than did a traditional low calcium diet over 5 years.

Normal calcium, low protein, low salt (intervention) diet $v$ a low calcium diet for men with hypercalciuria at 5 years (unadjusted analysis) †

\begin{tabular}{lllll} 
Outcome & $\begin{array}{l}\text { Intervention } \\
\text { diet }\end{array}$ & Low calcium diet & RRR (95\% CI) & NNT (CI) \\
$\begin{array}{l}\text { Recurrence of } \\
\text { stones }\end{array}$ & $20 \%$ & $38 \%$ & $51 \%(2$ to 76$)$ & 6 (3 to 50$)$ \\
\hline
\end{tabular}

†Abbreviations defined in glossary; RRR, NNT, and $\mathrm{Cl}$ calculated from point estimates reported in article.

*See glossary.

\section{COMMENTARY}

Calcium oxalate kidney stones are common, costly, painful, and preventable. Dietary modification, particularly calcium restriction, has been a hallmark of prevention but has never been shown to be beneficial. Observational studies in the mid-1990s found that a higher dietary calcium intake was associated with a reduced risk for incident stone formation. ${ }^{12}$ However, the question remained whether increasing dietary calcium would reduce the risk for recurrent stone formation, particularly in individuals with hypercalciuria.

The seminal trial by Borghi et al showed that a normal to high calcium, low sodium, low animal protein diet reduced the risk for stone recurrence in patients with hypercalciuria. Notably, urinary calcium actually decreased in the intervention group, probably because of the substantial reduction in sodium and animal protein intake. The relatively low dropout rate and high compliance are encouraging. One note of caution is that the mean baseline urinary calcium levels were high $(>400 \mathrm{mg} / \mathrm{d})$, even for patients with recurrent stones.

Two clinically relevant applications of these findings emerge. Firstly, and most important, dietary calcium restriction in patients with hypercalciuria can lead to a negative calcium balance and decreased bone mineral density. Secondly, relatively simple dietary modifications can lead to beneficial changes in urine composition and reduce the likelihood of stone recurrence.

Several questions remain to be answered. Is dietary modification as effective in patients with less extreme urinary values? What are the relative contributions of higher calcium, lower animal protein, and lower sodium to reduced stone recurrence? For patients who prefer to avoid dairy products (the major source of dietary calcium), do calcium supplements work as well if taken at mealtime? Can this dietary approach also reduce the risk for recurrence in patients with calcium phosphate stones?

Patients and providers should be aware of this evidence supporting the benefits of dietary and fluid modifications to prevent stone recurrence. Physicians should stop restricting calcium intake.

Gary Curhan, MD, ScD Harvard Medical School Boston, Massachusetts, USA

1 Curhan GC, Willett WC, Rimm EB, et al. A prospective study of dietary calcium and other nutrients and the risk of symptomatic kidney stones. $N$ Engl I Med 1993;328:833-8.

2 Curhan GC, Willett WC, Speizer FE, et al. Comparison of dietary calcium with supplemental calcium and other nutrients as factors affecting the risk for kidney stones in women. Ann Intern Med 1997;126:497-504. 